\title{
On iterative fixed point convergence in uniformly convex Banach space and Hilbert space
}

\author{
Julee Srivastava and Neeta Singh
}

\begin{abstract}
Some fixed point convergence properties are proved for compact and demicompact maps acting over closed, bounded and convex subsets of a real Hilbert space. We also show that for a generalized nonexpansive mapping in a uniformly convex Banach space the Ishikawa iterates converge to a fixed point. Finally, a convergence type result is established for multivalued contractive mappings acting on closed subsets of a complete metric space. These are extensions of results in Ciric, et. al. [7], Panyanak [2] and Agarwal, et. al. [9].
\end{abstract}

\section{Introduction}

Let $H$ be a Hilbert space and $K$ be a nonempty subset of $H$. A mapping $T: K \rightarrow H$ is said to be pseudo-contractive if

$$
\|T x-T y\|^{2} \leq\|x-y\|^{2}+\|(I-T) x-(I-T) y\|^{2}, \text { for all } x, y \in K .
$$

A mapping $T: K \rightarrow H$ is called hemicontractive if $F(T)=\{x \in K: T x=$ $x\} \neq \phi$ and

$\left\|T x-x^{*}\right\|^{2} \leq\left\|x-x^{*}\right\|^{2}+\|x-T x\|^{2}, \quad$ for all $x^{*} \in F(T)$ and for all $x \in K$.

Key Words: Ishikawa iterates, Pseudo-contractive mapping, Hilbert space, Fixed points, Multivalued map.

2010 Mathematics Subject Classification: 47H10, 54H60.

Received: August, 2011.

Revised: January, 2011.

Accepted: February, 2012. 
It is easy to observe that each pseudo-contractive mapping with fixed points is hemicontractive. The reciprocal is not in general true; see [1],[4].

There are two well known methods of approximating a fixed point of a pseudo-contractive mapping, viz. Mann [11] iterative and Ishikawa [10] iterative processes. In 1991, Xu [3] introduced the following iteration process: For $T: K \rightarrow E$, let a sequence $\left\{x_{n}\right\}$ and $x_{0} \in K$, where $K$ is a nonempty subset of a Banach space $E$, defined iteratively as follows :

$$
\begin{aligned}
x_{n+1} & =a_{n} x_{n}+b_{n} T y_{n}+c_{n} u_{n} \\
y_{n} & =a_{n}{ }^{\prime} x_{n}+b_{n}{ }^{\prime} T x_{n}+c_{n}{ }^{\prime} v_{n}, \quad n \geq 0,
\end{aligned}
$$

where $\left\{u_{n}\right\}$ and $\left\{v_{n}\right\}$ are bounded sequences in $K$ and $\left\{a_{n}\right\},\left\{b_{n}\right\},\left\{c_{n}\right\},\left\{a_{n}^{\prime}\right\}$, $\left\{b_{n}^{\prime}\right\}$ and $\left\{c_{n}^{\prime}\right\}$ are sequences in $[0,1]$, such that $a_{n}+b_{n}+c_{n}=a_{n}^{\prime}+b_{n}^{\prime}+c_{n}^{\prime}=1$, for all $n \geq 1$. If, in (1), $b_{n}^{\prime}=0=c_{n}^{\prime}$, then we obtain the Mann iterative sequence in the sense of Xu. If $c_{n}=0=c_{n}^{\prime}$ in (1), then we obtain the Ishikawa iterative sequence.

In [7], Ciric, et al. have introduced and investigated the following modified Mann implicit iterative process. Let $K$ be a closed convex subset of a real normed space $N$ and $T: K \rightarrow K$ be a mapping. Define $\left\{x_{n}\right\}$ in $K$ as follows :

$$
\begin{aligned}
& x_{0} \in K, \\
& x_{n}=a_{n} x_{n-1}+b_{n} T v_{n}+c_{n} u_{n}, \quad n \geq 1,
\end{aligned}
$$

where $\left\{a_{n}\right\},\left\{b_{n}\right\},\left\{c_{n}\right\}$ are real sequences in $[0,1]$ such that $a_{n}+b_{n}+c_{n}=1$, for each $n \in \mathbb{N}$ and $\left\{u_{n}\right\}$ and $\left\{v_{n}\right\}$ are sequences in $K$.

Let $H$ be a Hilbert space and $C$ a subset of $H$. A mapping $T: C \rightarrow H$ is called demicompact if it has the property that whenever $\left\{u_{n}\right\}$ is bounded sequence in $H$ and $\left\{T u_{n}-u_{n}\right\}$ is strongly convergent, there exists a strongly convergent subsequence $\left\{u_{n_{k}}\right\}$ of $\left\{u_{n}\right\}$.

In section two of the present paper, we have shown that if $K$ is closed, bounded and convex subset of a real Hilbert space $H, T: K \rightarrow K$ a compact hemicontractive map with $x_{0} \in T(K)$ and sequence $\left\{x_{n}\right\}$ in $T(K)$ be defined by (1) and $\left\{b_{n}\right\},\left\{c_{n}\right\}$ and $\left\{v_{n}\right\}$ satisfy some appropriate conditions, then the sequence $\left\{x_{n}\right\}$ converges strongly to a fixed point of $T$. Also, we have investigated that if $K$ is closed, bounded and convex subset of a real Hilbert space $H$ and the mapping $T: K \rightarrow K$ is continuous demicompact hemicontractive map and $\left\{a_{n}\right\},\left\{b_{n}\right\},\left\{c_{n}\right\}$ are real sequences in $[0,1]$ such that $a_{n}+b_{n}+c_{n}=1$, for each $n \in \mathbb{N}$ and $\left\{b_{n}\right\},\left\{c_{n}\right\},\left\{v_{n}\right\}$ satisfy some appropriate conditions, then the sequence $\left\{x_{n}\right\}$, defined by $(2)$, converges strongly to some fixed point of $T$. 
Let $E$ be a Banach space. A subset $K$ of $E$ is called proximinal if for each $x \in E$, there exists an element $k \in K$ such that

$$
d(x, k)=\operatorname{dist}(x, K)=\inf \{\|x-y\|: y \in K\} .
$$

It is well known that every closed convex subset of a uniformly convex Banach space is proximinal. We shall denote by $P(K)$, the family of nonempty bounded proximinal subsets of $K$. We say that the mapping $T: E \rightarrow P(E)$ is generalized nonexpansive if

$$
H(T x, T y) \leq a\|x-y\|+b\{d(x, T x)+d(y, T y)\}+c\{d(x, T y)+d(y, T x)\},
$$

for all $x, y \in X$, where $a+2 b+2 c \leq 1$.

Bancha Panyanak proved the following Theorem in [2].

Theorem 1.1. Let $K$ be a nonempty compact convex subset of a uniformly convex Banach Space E. Suppose T:K $\rightarrow P(K)$ is a nonexpansive map with a fixed point $p$. Let $\left\{x_{n}\right\}$ be the sequence of Ishikawa iterates defined by $x_{0} \in K$,

$$
y_{n}=\left(1-\beta_{n}\right) x_{n}+\beta_{n} z_{n} \quad \beta_{n} \in[0,1], \quad n \geq 0,
$$

where $z_{n} \in T x_{n}$ is such that $\left\|z_{n}-p\right\|=\operatorname{dist}\left(p, T x_{n}\right)$, and

$$
x_{n+1}=\left(1-\alpha_{n}\right) x_{n}+\alpha_{n} z_{n}{ }^{\prime}, \quad \alpha_{n} \in[0,1],
$$

where $z_{n}{ }^{\prime} \in T y_{n}$ is such that $\left\|z_{n}{ }^{\prime}-p\right\|=\operatorname{dist}\left(p, T y_{n}\right)$. Assume that

(i) $0 \leq \alpha_{n}, \beta_{n}<1$,

(ii) $\beta_{n} \rightarrow 0$ and

(iii) $\sum \alpha_{n} \beta_{n}=\infty$. Then the sequence $\left\{x_{n}\right\}$ converges to a fixed point of $T$.

In section three, we generalize the above theorem by taking generalized nonexpansive map in place of nonexpansive map in which the sequence of Ishikawa iterates converges to the fixed point of $T$.

Let $X$ be a complete metric space and $C(X)$ is collection of all nonempty closed subsets of $X, C B(X)$ is the collection of all nonempty closed bounded subsets of $X$. Let $H$ be a Hausdorff metric on $C(X)$, that is

$$
H(A, B)=\max \left\{\sup _{x \in A} d(x, B), \sup _{x \in B} d(x, A)\right\},
$$

for any $A, B \in C(X)$, where $d(x, B)=\inf \{\|x-y\|: y \in B\}$.

A function $f: X \rightarrow \mathbb{R}$ is called lower semi-continuous, if for any sequence $\left\{x_{n}\right\}$ in $X$ and $x \in X$,

$$
x_{n} \rightarrow x \Longrightarrow f(x) \leq \underline{\lim }_{n \rightarrow \infty} f\left(x_{n}\right) .
$$

In section four, we generalize the following result (cf. Theorem 4.2.11 in [9]) by taking $C(X)$ in place of $C B(X)$. 
Theorem 1.2. [9]. Let $X$ be a complete metric space and let $T_{n}: X \rightarrow$ $C B(X)(n=0,1,2,3, \ldots)$ be contraction mappings each having Lipschitz constant $k<1$, i.e.,

$$
H\left(T_{n} x, T_{n} y\right) \leq k d(x, y),
$$

for all $x, y \in X$ and $n \in(0,1,2,3, \ldots)$. If $\lim _{n \rightarrow \infty} H\left(T_{n}(x), T_{0}(x)\right)=0$ uniformly for $x \in X$, then $\lim _{n \rightarrow \infty} H\left(F\left(T_{n}\right), F\left(T_{0}\right)\right)=0$.

\section{Fixed point theorems for hemicontractive map}

We shall make use of the following Lemmas.

Lemma 2.1. [8]. Let $H$ be a Hilbert space, then for all $x, y, z \in H$,

$\|a x+b y+c z\|^{2}=a\|x\|^{2}+b\|y\|^{2}+c\|z\|^{2}-a b\|x-y\|^{2}-b c\|y-z\|^{2}-c a\|z-x\|^{2}$, where $a, b, c \in[0,1]$ and $a+b+c=1$.

Lemma 2.2. [5]. Suppose that $\left\{\rho_{n}\right\},\left\{\sigma_{n}\right\}$ are two sequences of nonnegative numbers such that for some real number $N_{0} \geq 1$,

$$
\rho_{n+1} \leq \rho_{n}+\sigma_{n}, \quad \forall n \geq N_{0} .
$$

(a) If $\sum_{n=1}^{\infty} \sigma_{n}<\infty$, then $\lim \left\{\rho_{n}\right\}$ exists.

(b) If $\sum_{n=1}^{\infty} \sigma_{n}<\infty$ and $\left\{\rho_{n}\right\}$ has a subsequence converging to zero, then $\lim _{n \rightarrow \infty} \rho_{n}=0$.

Now we prove our main results in this section which is generalization of [[7], Theorem 4]

Theorem 2.3. Let $K$ be a closed bounded convex subset of a real Hilbert space $H$ and $T: K \rightarrow K$ a compact, hemicontractive map. Let $\left\{a_{n}\right\},\left\{b_{n}\right\},\left\{c_{n}\right\}$ be real sequences in $[0,1]$ such that $a_{n}+b_{n}+c_{n}=1$, for each $n \in \mathbb{N}$ and satisfying:

(i) $\left\{b_{n}\right\} \subset[\delta, 1-\delta]$ for some $\delta \in(0,1 / 2]$,

(ii) $\sum_{n=1}^{\infty} c_{n}<\infty$.

For arbitrary $x_{0} \in T(K)$, let a sequence $\left\{x_{n}\right\}$ in $T(K)$ be iteratively defined by

$$
x_{n}=a_{n} x_{n-1}+b_{n} T v_{n}+c_{n} u_{n}, \quad n \geq 1,
$$

where $v_{n} \in T(K)$ are chosen such that $\sum_{n=1}^{\infty}\left\|v_{n}-x_{n}\right\|<\infty$ and $\left\{u_{n}\right\}_{n=1}^{\infty}$ is arbitrary sequence in $K$. Then $\left\{x_{n}\right\}_{n=1}^{\infty}$ converges strongly to some fixed point of $T$. 
Proof. Let $T: K \rightarrow K$ be a continuous map, where $K$ is a closed bounded convex subset of a real Hilbert space $H$. Then $T(K)$ is closed subset of $K$ and $\overline{T(K)}$ is compact. Hence $T(K)$ is compact. Let $A=\overline{c o}(T(K))$, convex closure of $T(K)$. Then $A \subset K$. Since $T(K)$ is a relatively compact subset of $K$, by Mazur's theorem $\overline{c o}(T(K))$ is compact and convex. Furthermore, $T(A) \subset A$. Now we have to show that in restriction $T: A \rightarrow A,\left\{x_{n}\right\}_{n=1}^{\infty}$ converges strongly to some fixed point of $T$. Let $x^{*} \in T(K)$ be a fixed point of $T$ and $M=\operatorname{diam}(T(K))$, diameter of $T(K)$. Since $T$ is hemicontractive,

$$
\left\|T v_{n}-x^{*}\right\|^{2} \leq\left\|v_{n}-x^{*}\right\|^{2}+\left\|v_{n}-T v_{n}\right\|^{2},
$$

for each $n \in \mathbb{N}$. By virtue of (3), Lemma 2.1 and (4), we obtain

$$
\begin{aligned}
\left\|x_{n}-x^{*}\right\|^{2}= & \left\|a_{n} x_{n-1}+b_{n} T v_{n}+c_{n} u_{n}-x^{*}\right\|^{2} \\
= & \left\|a_{n}\left(x_{n-1}-x^{*}\right)+b_{n}\left(T v_{n}-x^{*}\right)+c_{n}\left(u_{n}-x^{*}\right)\right\|^{2} \\
= & a_{n}\left\|x_{n-1}-x^{*}\right\|^{2}+b_{n}\left\|T v_{n}-x^{*}\right\|^{2}+c_{n}\left\|u_{n}-x^{*}\right\|^{2} \\
& -a_{n} b_{n}\left\|x_{n-1}-T v_{n}\right\|^{2}-b_{n} c_{n}\left\|T v_{n}-u_{n}\right\|^{2} \\
& -a_{n} c_{n}\left\|x_{n-1}-u_{n}\right\|^{2} \\
\leq & a_{n}\left\|x_{n-1}-x^{*}\right\|^{2}+b_{n}\left\|T v_{n}-x^{*}\right\|^{2} \\
& \quad+c_{n}\left\|u_{n}-x^{*}\right\|^{2}-a_{n} b_{n}\left\|x_{n-1}-T v_{n}\right\|^{2} \\
\leq & \left(1-b_{n}\right)\left\|x_{n-1}-x^{*}\right\|^{2}+b_{n}\left(\left\|v_{n}-x^{*}\right\|^{2}\right. \\
& \left.+\left\|v_{n}-T v_{n}\right\|^{2}\right)+c_{n} M^{2}-a_{n} b_{n}\left\|x_{n-1}-T v_{n}\right\|^{2} .
\end{aligned}
$$

Also, we have

$$
\begin{aligned}
\left\|v_{n}-x^{*}\right\|^{2} & \leq\left\|v_{n}-x_{n}\right\|^{2}+\left\|x_{n}-x^{*}\right\|^{2}+2\left\|x_{n}-x^{*}\right\|\left\|v_{n}-x_{n}\right\| \\
& \leq\left\|v_{n}-x_{n}\right\|^{2}+\left\|x_{n}-x^{*}\right\|^{2}+2 M\left\|v_{n}-x_{n}\right\|
\end{aligned}
$$

and

$$
\begin{aligned}
\left\|v_{n}-T v_{n}\right\|^{2} & \leq\left\|v_{n}-x_{n}\right\|^{2}+\left\|x_{n}-T v_{n}\right\|^{2}+2\left\|x_{n}-T v_{n}\right\|\left\|v_{n}-x_{n}\right\| \\
& \leq\left\|v_{n}-x_{n}\right\|^{2}+\left\|x_{n}-T v_{n}\right\|^{2}+2 M\left\|v_{n}-x_{n}\right\|
\end{aligned}
$$

and

$$
\begin{aligned}
\left\|x_{n}-T v_{n}\right\|^{2} & =\left\|a_{n} x_{n-1}+b_{n} T v_{n}+c_{n} u_{n}-T v_{n}\right\|^{2} \\
& =\left\|\left(1-b_{n}-c_{n}\right) x_{n-1}+b_{n} T v_{n}+c_{n} u_{n}-T v_{n}\right\|^{2} \\
& \leq\left[\left(1-b_{n}\right)\left\|x_{n-1}-T v_{n}\right\|+c_{n}\left\|u_{n}-x_{n-1}\right\|\right]^{2} \\
& \leq\left[\left(1-b_{n}\right)\left\|x_{n-1}-T v_{n}\right\|+M c_{n}\right]^{2} \\
& \leq\left(1-b_{n}\right)^{2}\left\|x_{n-1}-T v_{n}\right\|^{2}+3 M^{2} c_{n} .
\end{aligned}
$$


In view of (7) and (8), (5) takes the form

$$
\begin{aligned}
\left\|x_{n}-x^{*}\right\|^{2} \leq & \left(1-b_{n}\right)^{2}\left\|x_{n-1}-x^{*}\right\|^{2} \\
& +b_{n}\left\|x_{n}-x^{*}\right\|^{2}+2 b_{n}\left\|v_{n}-x_{n}\right\|^{2}+4 M b_{n}\left\|v_{n}-x_{n}\right\| \\
& +4 M^{2} c_{n}-b_{n}\left[a_{n}-\left(1-b_{n}\right)^{2}\right]\left\|x_{n-1}-T v_{n}\right\|^{2} .
\end{aligned}
$$

Using $a_{n}+b_{n}+c_{n}=1$ in condition $(i)$, we have

$$
\begin{aligned}
a_{n}-\left(1-b_{n}\right)^{2} & =1-b_{n}-c_{n}-\left(1-b_{n}\right)^{2} \\
& =b_{n}\left(1-b_{n}\right)-c_{n} \\
& \geq \delta^{2}-c_{n} .
\end{aligned}
$$

From condition $(\mathrm{ii})$, it follows that there exists a positive integer $n_{0} \in \mathbb{N}$ such that for all $n \geq n_{0}$, we have $c_{n} \leq \delta^{3}$, i.e. $\delta^{2}-c_{n} \geq \delta^{2}-\delta^{3}=\delta^{2}(1-\delta)$. Thus, from (10), we obtain

$$
a_{n}-\left(1-b_{n}\right)^{2} \geq \delta^{2}(1-\delta)
$$

From (9) and (11), we have, for all $n \geq n_{0}$

$$
\begin{aligned}
\left(1-b_{n}\right)\left\|x_{n}-x^{*}\right\|^{2} \leq & \left(1-b_{n}\right)\left\|x_{n-1}-x^{*}\right\|^{2}+2 b_{n}\left\|v_{n}-x_{n}\right\|^{2} \\
& +4 M b_{n}\left\|v_{n}-x_{n}\right\|+4 M^{2} c_{n} \\
& -b_{n} \delta^{2}(1-\delta)\left\|x_{n-1}-T v_{n}\right\|^{2} . \\
\text { or }\left\|x_{n}-x^{*}\right\|^{2} \leq & \left\|x_{n_{1}}-x^{*}\right\|^{2}+\frac{2 b_{n}}{\left(1-b_{n}\right)}\left\|v_{n}-x_{n}\right\|^{2} \\
& +4 M \frac{b_{n}}{\left(1-b_{n}\right)}\left\|v_{n}-x_{n}\right\|+\frac{4 M^{2} c_{n}}{\left(1-b_{n}\right)} \\
& +b_{n} \frac{\delta^{2}(1-\delta)}{\left(1-b_{n}\right)}\left\|x_{n-1}-T v_{n}\right\|^{2} .
\end{aligned}
$$

Since $\frac{1}{\left(1-b_{n}\right)} \leq \frac{1}{\delta}$ and $\frac{-1}{\left(1-b_{n}\right)} \leq \frac{-1}{1-\delta} ; \delta \leq b_{n} \leq 1-\delta$, we have $\frac{b_{n}}{1-b_{n}} \leq \frac{1-\delta}{\delta}=$ 
$\frac{1}{\delta}-1<\frac{1}{\delta}$. Hence from (12), we have

$$
\begin{aligned}
\left\|x_{n}-x^{*}\right\|^{2} \leq & \left\|x_{n-1}-x^{*}\right\|^{2}+\frac{2}{\delta}\left\|v_{n}-x_{n}\right\|^{2}+\frac{4 M}{\delta}\left\|v_{n}-x_{n}\right\|+\frac{4 M^{2} c_{n}}{\delta} \\
& -\frac{\delta^{3}(1-\delta)}{\left(1-b_{n}\right)}\left\|x_{n-1}-T v_{n}\right\|^{2} \\
\leq & \left\|x_{n-1}-x^{*}\right\|^{2}+\frac{2}{\delta}\left\|v_{n}-x_{n}\right\|^{2}+\frac{4 M}{\delta}\left\|v_{n}-x_{n}\right\|+\frac{4 M^{2} c_{n}}{\delta} \\
& -\frac{\delta^{3}(1-\delta)}{(1-\delta}\left\|x_{n-1}-T v_{n}\right\|^{2} \\
\leq & \left\|x_{n-1}-x^{*}\right\|^{2}+\frac{2}{\delta}\left\|v_{n}-x_{n}\right\|^{2}+\frac{4 M}{\delta}\left\|v_{n}-x_{n}\right\|+\frac{4 M^{2} c_{n}}{\delta} \\
& -\delta^{3}\left\|x_{n-1}-T v_{n}\right\|^{2},
\end{aligned}
$$

i.e. $\left\|x_{n}-x^{*}\right\|^{2} \leq\left\|x_{n-1}-x^{*}\right\|^{2}-\delta^{3}\left\|x_{n-1}-T v_{n}\right\|^{2}+\sigma_{n}$, for all $n \geq n_{0}$,

where

$$
\begin{aligned}
\sigma_{n} & =\left[\frac{2}{\delta}\left\|v_{n}-x_{n}\right\|^{2}+\frac{4 M}{\delta}\left\|v_{n}-x_{n}\right\|+\frac{4 M^{2}}{\delta} c_{n}\right] \\
& =\frac{1}{\delta}\left[2\left\|v_{n}-x_{n}\right\|^{2}+4 M\left\|v_{n}-x_{n}\right\|+4 M^{2} c_{n}\right] .
\end{aligned}
$$

By the hypothesis of the theorem, we obtain

$$
\sum_{j=n_{0}}^{\infty} \sigma_{j}<+\infty
$$

From (14), we get

$\delta^{3}\left\|x_{n-1}-T v_{n}\right\|^{2} \leq\left\|x_{n-1}-x^{*}\right\|^{2}-\left\|x_{n}-x^{*}\right\|^{2}+\sigma_{n}$,

and hence

$$
\delta^{3} \sum_{j=n_{0}}^{\infty}\left\|x_{j-1}-T v_{j}\right\|^{2} \leq \sum_{j=n_{0}}^{\infty} \sigma_{j}+\left\|x_{n_{0}-1}-x^{*}\right\|^{2} .
$$

By (15) we get $\sum_{j=n_{0}}^{\infty}\left\|x_{j-1}-T v_{j}\right\|^{2}<+\infty$. This implies $\lim _{n \rightarrow \infty}\left\|x_{n-1}-T v_{n}\right\|$ $=0$. From (8) and condition (ii), it further implies that $\lim _{n \rightarrow \infty}\left\|x_{n}-T v_{n}\right\|=$ 0 . Also the condition $\sum_{j=n_{0}}^{\infty}\left\|v_{n}-x_{n}\right\|<\infty$ implies $\lim _{n \rightarrow \infty}\left\|v_{n}-x_{n}\right\|=0$. Thus from (7), we have

$$
\lim _{n \rightarrow \infty}\left\|v_{n}-T v_{n}\right\|=0
$$


By compactness of $\overline{T(K)}$, there is a convergent subsequence $\left\{v_{n_{j}}\right\}$ of $\left\{v_{n}\right\}$, such that it converges to some point $z \in \overline{T(K)} \subset \overline{c o}(T(K))=A$. By continuity of $T,\left\{T v_{n_{j}}\right\}$ converges to $T z$. Therefore, from (16), we conclude that $T z=z$. Further, $\lim _{n \rightarrow \infty}\left\|v_{n}-x_{n}\right\|=0$ implies

$$
\lim _{j \rightarrow \infty}\left\|x_{n_{j}}-z\right\|=0
$$

Since (13) holds for any fixed points of $T$, we have

$$
\left\|x_{n}-z\right\|^{2} \leq\left\|x_{n-1}-z\right\|^{2}-\delta^{3}\left\|x_{n-1}-T v_{n}\right\|^{2}+\sigma_{n}
$$

and in view of (15), (17) and Lemma 2.2, we conclude that $\left\|x_{n}-z\right\| \rightarrow 0$ as $n \rightarrow \infty$ i.e $x_{n} \rightarrow z$ as $n \rightarrow \infty$. Thus, we have proved that a sequence $\left\{x_{n}\right\}$ converges strongly to some fixed point of $T$. This sequence in $K$ automatically converges strongly to a fixed point of $T$.

Theorem 2.4. Let $K$ be a closed bounded convex subset of a real Hilbert space $H$ and $T: K \rightarrow K$ a continuous demicompact and hemicontractive map. Let $\left\{a_{n}\right\},\left\{b_{n}\right\}$ and $\left\{c_{n}\right\}$ be a real sequences in $[0,1]$ such that $a_{n}+b_{n}+c_{n}=1$ for each $n \in \mathbb{N}$ and satisfying:

(i) $\left\{b_{n}\right\} \subset[\delta, 1-\delta]$, for some $\delta \in\left(0, \frac{1}{2}\right]$,

(ii) $\sum_{n=1}^{\infty} c_{n}<\infty$.

For arbitrary $x_{0} \in K$, let a sequence $x_{n} \in K$ be iteratively defined by

$$
x_{n}=a_{n} x_{n-1}+b_{n} T v_{n}+c_{n} u_{n}, \quad n \geq 1,
$$

where $v_{n} \in K$ are chosen such that $\sum_{n=1}^{\infty}\left\|v_{n}-x_{n}\right\|<\infty$. Then $\left\{x_{n}\right\}_{n=1}^{\infty}$ converges strongly to some fixed point of $T$.

Proof. Let $x^{*} \in K$ be a fixed point of hemicontractive map $T$ and $M=$ $\operatorname{diam}(K)$. Using inequality (4) as in the proof of Theorem 2.3 and proceeding in the similar manner we arrive at (16) which implies that the sequence $\left\{v_{n}-\right.$ $\left.T v_{n}\right\}_{n \in N}$ converges strongly to zero. As $T$ is demicompact, it results that there exists a strongly convergent subsequence $\left\{v_{n_{j}}\right\}$ of $\left\{v_{n}\right\}$. such that $v_{n_{j}} \rightarrow$ $z \in K$. By continuity of $T, T v_{n_{j}}$ converges to $T z$. Therefore, from (16), we conclude that $T z=z$. Further, $\lim _{n \rightarrow \infty}\left\|v_{n}-x_{n}\right\|=0$ implies

$$
\left\|x_{n_{j}}-z\right\|=0 \text {. }
$$

Since (13) holds for any fixed points of $T$, we have

$$
\left\|x_{n}-z\right\|^{2} \leq\left\|x_{n-1}-z\right\|^{2}-\delta^{3}\left\|x_{n-1}-T v_{n}\right\|^{2}+\sigma_{n} .
$$

In view of (15), (19) and Lemma 2.2, we conclude that $\left\|x_{n}-z\right\| \rightarrow 0$ as $n \rightarrow \infty$ i.e. $x_{n} \rightarrow z$ as $n \rightarrow \infty$. Thus, we have proved that $\left\{x_{n}\right\}$ converges strongly to some fixed point of $T$. 


\section{Ishikawa iteration for multivalued generalized nonex- pansive map}

To prove the main theorem of this section, we need the following Lemmas:

Lemma 3.1. [3]. Let $E$ be a Banach space. Then $E$ is uniformly convex if and only if for any given number $\rho>0$, the square norm $\|.\|^{2}$ of $E$ is uniformly convex on $B_{\rho}$, the closed ball centered at the origin with radius $\rho$; namely, there exists a continuous strictly increasing function $\phi:[0, \infty) \rightarrow[0, \infty)$ with $\phi(0)=0$ such that

$$
\|\alpha x+(1-\alpha) y\|^{2} \leq \alpha\|x\|^{2}+(1-\alpha)\|y\|^{2}-\alpha(1-\alpha) \phi(\|x-y\|),
$$

for all $x, y \in B_{\rho}, \alpha \in[0,1]$.

Lemma 3.2. [2]. Let $\left\{\alpha_{n}\right\},\left\{\beta_{n}\right\}$ be two real sequences such that

(i) $0 \leq \alpha_{n}, \beta_{n}<1$,

(ii) $\beta_{n} \rightarrow 0$ as $n \rightarrow \infty$ and

(iii) $\sum_{n=1}^{\infty} \alpha_{n} \beta_{n}=\infty$.

Let $\left\{\gamma_{n}\right\}$ be a nonnegative real sequence such that $\sum_{n=1}^{\infty} \alpha_{n} \beta_{n}\left(1-\beta_{n}\right) \gamma_{n}$ is bounded. Then $\left\{\gamma_{n}\right\}$ has a subsequence which converges to zero.

Theorem 3.3. Let $K$ be a nonempty compact convex subset of a uniformly convex Banach space $E$. Suppose $T: K \rightarrow P(K)$ is a generalized nonexpansive map with a fixed point $p$. Let $\left\{x_{n}\right\}$ be the sequence of Ishikawa iterates defined by $x_{0} \in K$,

$$
y_{n}=\left(1-\beta_{n}\right) x_{n}+\beta_{n} z_{n} \quad \beta_{n} \in[0,1], n \geq 0,
$$

where $z_{n} \in T x_{n}$ is such that $\left\|z_{n}-p\right\|=\operatorname{dist}\left(p, T x_{n}\right)$, and

$$
x_{n+1}=\left(1-\alpha_{n}\right) x_{n}+\alpha_{n} z_{n}{ }^{\prime}, \quad \alpha_{n} \in[0,1]
$$

where $z_{n}{ }^{\prime} \in T y_{n}$ is such that $\left\|z_{n}{ }^{\prime}-p\right\|=\operatorname{dist}\left(p, T y_{n}\right)$. Assume that

(i) $0 \leq \alpha_{n}, \beta_{n}<1$

(ii) $\beta_{n} \rightarrow 0$ and

(iii) $\sum_{n=1}^{\infty} \alpha_{n} \beta_{n}=\infty$. Then the sequence $\left\{x_{n}\right\}$ converges to a fixed point of $T$.

Proof. By using Lemma 3.1, we have

$$
\begin{aligned}
\left\|x_{n+1}-p\right\|^{2}= & \left\|\left(1-\alpha_{n}\right) x_{n}+\alpha_{n} z_{n}{ }^{\prime}-p\right\|^{2} \\
\leq & \left(1-\alpha_{n}\right)\left\|x_{n}-p\right\|^{2}+\alpha_{n}\left\|z_{n}{ }^{\prime}-p\right\|^{2}-\alpha_{n}\left(1-\alpha_{n}\right) \phi\left(\left\|x_{n}-z_{n}{ }^{\prime}\right\|\right) \\
\leq & \left(1-\alpha_{n}\right)\left\|x_{n}-p\right\|^{2}+\alpha_{n} H^{2}\left(T y_{n}, T p\right) \\
& -\alpha_{n}\left(1-\alpha_{n}\right) \phi\left(\left\|x_{n}-z_{n}{ }^{\prime}\right\|\right) .
\end{aligned}
$$


By generalized nonexpansive property of $T$, we have

$$
\begin{aligned}
H\left(T p, T y_{n}\right) & \leq a\left\|y_{n}-p\right\|+b d\left(y_{n}, T y_{n}\right)+c\left\{d\left(p, T y_{n}\right)+d\left(y_{n}, T p\right)\right\} \\
& \leq a\left\|y_{n}-p\right\|+b\left\{\left\|y_{n}-p\right\|+d\left(p, T y_{n}\right)\right\}+c\left\{d\left(p, T y_{n}\right)+d\left(y_{n}, T p\right)\right\} \\
& \leq(a+b+c)\left\|y_{n}-p\right\|+(b+c) d\left(p, T y_{n}\right) \\
& \leq(a+b+c)\left\|y_{n}-p\right\|+(b+c) H\left(T p, T y_{n}\right) \\
H\left(T p, T y_{n}\right) & \leq \frac{a+b+c}{1-(b+c)}\left\|y_{n}-p\right\| .
\end{aligned}
$$

Since $\frac{a+b+c}{1-(b+c)} \leq 1$, it follows that

$$
H\left(T y_{n}, T p\right) \leq\left\|y_{n}-p\right\|
$$

From (21) and (23), we get

$$
\begin{aligned}
\left\|x_{n+1}-p\right\|^{2} \leq & \left(1-\alpha_{n}\right)\left\|x_{n}-p\right\|^{2}+\alpha_{n}\left\|y_{n}-p\right\|^{2} \\
& -\alpha_{n}\left(1-\alpha_{n}\right) \phi\left(\left\|x_{n}-z_{n}^{\prime}\right\|\right) .
\end{aligned}
$$

Now

$$
\begin{aligned}
\left\|y_{n}-p\right\|^{2} & =\left\|\left(1-\beta_{n}\right) x_{n}+\beta_{n} z_{n}-p\right\|^{2} \\
& \leq\left(1-\beta_{n}\right)\left\|x_{n}-p\right\|^{2}+\beta_{n}\left\|z_{n}-p\right\|^{2}-\beta_{n}\left(1-\beta_{n}\right) \phi\left(\left\|x_{n}-z_{n}\right\|\right) \\
& \leq\left(1-\beta_{n}\right)\left\|x_{n}-p\right\|^{2}+\beta_{n} H^{2}\left(T x_{n}, T p\right)-\beta_{n}\left(1-\beta_{n}\right) \phi\left(\left\|x_{n}-z_{n}\right\|\right) \\
& \leq\left\|x_{n}-p\right\|^{2}-\beta_{n}\left(1-\beta_{n}\right) \phi\left(\left\|x_{n}-z_{n}\right\|\right) .
\end{aligned}
$$

From (24) and (25), we get

$$
\left\|x_{n+1}-p\right\|^{2} \leq\left\|x_{n}-p\right\|^{2}-\alpha_{n} \beta_{n}\left(1-\beta_{n}\right) \phi\left(\left\|x_{n}-z_{n}\right\|\right) .
$$

Therefore

$$
\alpha_{n} \beta_{n}\left(1-\beta_{n}\right) \phi\left(\left\|x_{n}-z_{n}\right\|\right) \leq\left\|x_{n}-p\right\|^{2}-\left\|x_{n+1}-p\right\|^{2} .
$$

This implies

$$
\sum_{n=1}^{\infty} \alpha_{n} \beta_{n}\left(1-\beta_{n}\right) \phi\left(\left\|x_{n}-z_{n}\right\|\right) \leq\left\|x_{1}-p\right\|^{2}<\infty .
$$

By Lemma 3.2, there exists a subsequence $\left\{x_{n_{k}}-z_{n_{k}}\right\}$ of $\left\{x_{n}-z_{n}\right\}$ such that $\phi\left(\left\|x_{n_{k}}-z_{n_{k}}\right\|\right) \rightarrow 0$ as $k \rightarrow \infty$ and hence $\left\|x_{n_{k}}-z_{n_{k}}\right\| \rightarrow 0$, by continuity and 
strictly increasing nature of $\phi$. By compactness of $K$, we may assume that $x_{n_{k}} \rightarrow q$, for some $q \in K$. Thus,

$$
\begin{aligned}
\operatorname{dist}(q, T q) & \leq\left\|q-x_{n_{k}}\right\|+\operatorname{dist}\left(x_{n_{k}}, T x_{n_{k}}\right)+H\left(T x_{n_{k}}, T q\right) \\
& \leq\left\|q-x_{n_{k}}\right\|+\left\|x_{n_{k}}-z_{n_{k}}\right\|+\left\|x_{n_{k}}-q\right\| \rightarrow 0 \text { as } k \rightarrow \infty
\end{aligned}
$$

Hence $q$ is a fixed point of $T$. Now on taking $q$ in place of $p$, we get $\left\|x_{n}-q\right\|$ as a decreasing sequence by (26). Since $\left\|x_{n_{k}}-q\right\| \rightarrow 0$ as $k \rightarrow \infty$, it follows that $\left\{\left\|x_{n}-q\right\|\right\}$ converges to zero, so that the conclusion of the theorem follows.

\section{Fixed point theorem for multivalued contractive map- pings}

The main result of this section is as follows:

Proposition 4.1. Let $X$ be a complete metric space and let $S, T: X \rightarrow C(X)$ be a multivalued mapping. If there exists a constant $c \in(0,1)$ such that for any $x \in X$ there is $y \in I_{b}^{(S) x}$ and $I_{b}^{(T) x}$ satisfying $d(y, S(y)) \leq c d(x, y)$ and $d(y, T y) \leq c d(x, y)$ with $c<b$ and $f$ is lower semi-continuous, then

$$
H(F(s), F(T)) \leq(b-c)^{-1} \sup _{x \in X} H(S x, T x),
$$

where the following have been taken from [12], for mapping $f: X \rightarrow R$, $f(x)$ is defined as $f(x)=d(x, T x)$ and for mapping $S, f(x)$ is defined as $f(x)=d(x, S x)$,

$$
I_{b}^{(S) x}=\{y \in S(x): b d(x, y) \leq d(x, S x)\}
$$

and

$$
I_{b}^{(T) x}=\{y \in T(x): b d(x, y) \leq d(x, T x)\} .
$$

Proof. Since $S(x), T(x) \in C(X)$ for any $x \in X, I_{b}^{(S) x}$ and $I_{b}^{(T) x}$ are nonempty for any constant $b \in(0,1)$. Let $x_{0} \in F(S)$ implies $x_{0} \in S\left(x_{0}\right)$. Then there is another point $x_{1} \in S\left(x_{0}\right)$ such that for any initial point $x_{0} \in X$, there exists $x_{1} \in I_{b}^{s\left(x_{0}\right)}$. For $x_{1}$, there exists $S x_{1}$ such that

$$
d\left(x_{1}, S x_{1}\right) \leq c d\left(x_{0}, x_{1}\right),
$$

and for any $x_{0} \in X$, there exists $x_{1} \in I_{b}^{(T) x_{0}}$ i.e. $\left\{x_{1} \in T\left(x_{0}\right): b d\left(x_{0}, x_{1}\right) \leq\right.$ $\left.d\left(x_{0}, T x_{1}\right)\right\}$ satisfying

$$
d\left(x_{1}, T x_{1}\right) \leq \operatorname{cd}\left(x_{0}, x_{1}\right),
$$


and for $x_{1} \in X$, there is $x_{2} \in I_{b}^{(T) x_{1}}$ satisfying

$$
d\left(x_{2}, T x_{2}\right) \leq c d\left(x_{1}, x_{2}\right) .
$$

Continuing this process, we can get an iterative sequence $\left\{x_{n}\right\}_{n=0}^{\infty}$, where $x_{n+1} \in I_{b}^{(T) x_{n}}$ and

$$
d\left(x_{n+1}, T x_{n+1}\right) \leq c d\left(x_{n}, x_{n+1}\right), \quad n=0,1,2, \ldots
$$

On the other hand $x_{n+1} \in I_{b}^{(T) x_{n}}$ implies

$$
b d\left(x_{n}, x_{n+1}\right) \leq d\left(x_{n}, T x_{n}\right), \quad n=0,1,2, \ldots
$$

From (30) and (31), we have

$$
d\left(x_{n+1}, T x_{n+1}\right) \leq \frac{c}{b} d\left(x_{n}, T x_{n}\right), \quad n=0,1,2, \ldots
$$

and

$$
d\left(x_{n+1}, x_{n+2}\right) \leq \frac{c}{b} d\left(x_{n}, x_{n+1}\right), \quad n=0,1,2, \ldots
$$

Observe that

$$
\begin{aligned}
d\left(x_{n}, x_{n+1}\right) \leq & \frac{c}{b} d\left(x_{n-1}, x_{n}\right) \\
\leq & \frac{c}{b}\left[\frac{c}{b} d\left(x_{n-2}, x_{n-1}\right)\right] \\
= & \frac{c^{2}}{b^{2}} d\left(x_{n-2}, x_{n-1}\right) \\
& \cdots \\
& \cdots \\
& \cdots \\
= & \frac{c^{n}}{b^{n}} d\left(x_{0}, x_{1}\right) .
\end{aligned}
$$

Since $c<b, \frac{c}{b}<1$, therefore $\lim _{n \rightarrow \infty}\left(\frac{c}{b}\right)^{n} \rightarrow 0$, which means that $\left\{x_{n}\right\}_{n=0}^{\infty}$ is a Cauchy sequence. By the completeness of $X$, there exists $v \in X$ such that $\left\{x_{n}\right\}_{n=0}^{\infty}$ converges to $v$.

Now we have to show that $v \in F(T)$. We have given $\left\{f\left(x_{n}\right)\right\}_{n=0}^{\infty}=$ $\left\{d\left(x_{n}, T x_{n}\right)\right\}_{n=0}^{\infty}$ to be a decreasing sequence and hence it converges to zero. Since $f$ is lower semi-continuous, as $x_{n} \rightarrow v$, we have $0 \leq f(v) \leq \underline{\lim }_{n \rightarrow \infty} f\left(x_{n}\right)=$ 0 . Hence $f(v)=0$. Finally the closeness of $T(v)$ implies $v \in T(v)$. Hence 
$v \in F(T)$.

Now, we observe that

$$
\begin{aligned}
d\left(x_{0}, v\right) & \leq \sum_{n=0}^{\infty} d\left(x_{n}, x_{n+1}\right) \\
& \leq \sum_{n=0}^{\infty}\left(\frac{c}{b}\right)^{n} d\left(x_{0}, x_{1}\right) \\
& \leq\left(\frac{1}{1-\frac{c}{b}}\right) d\left(x_{0}, x_{1}\right) \\
& \leq\left(1-\frac{c}{b}\right)^{-1} \frac{1}{b} d\left(x_{0}, T x_{0}\right)
\end{aligned}
$$

Now

$$
\begin{aligned}
d\left(x_{0}, T x_{0}\right) & \leq \sup _{x \in S x_{0}} d\left(x, T x_{0}\right) \\
& \leq \max \left\{\sup _{x \in S x_{0}} d\left(x, T x_{0}\right), \sup _{x \in T x_{0}} d\left(x, S x_{0}\right)\right\} \\
& =H\left(S x_{0}, T x_{0}\right) .
\end{aligned}
$$

Hence we get

$$
\begin{aligned}
d\left(x_{0}, v\right) & \leq b(b-c)^{-1} \frac{1}{b} d\left(x_{0}, T x_{0}\right) \\
& \leq(b-c)^{-1} H\left(S x_{0}, T x_{0}\right) .
\end{aligned}
$$

Interchanging the roles of $S$ and $T$, for each $y_{0} \in F(T)$ and $y_{1} \in S y_{0}$, for any $y_{0} \in X$ and $u \in F(S)$, we have

$$
d\left(y_{0}, u\right) \leq(b-c)^{-1} H\left(S y_{0}, T y_{0}\right) .
$$

Thus, we have

$$
H(F(S), F(T)) \leq(b-c)^{-1} \sup _{x \in X} H(S x, T x) .
$$

Example Let $X=\left\{\frac{1}{2}, \frac{1}{4}, \frac{1}{8}, \ldots \ldots . \frac{1}{2^{n}}, \ldots\right\} \cup\{0,1\}, d(x, y)=|x-y|$ for any $x, y \in X$, be a complete metric space. Define the mappings $S, T: X \rightarrow C(X)$ as and

$$
S(x)=\left\{\begin{array}{c}
\left\{\frac{1}{2^{n+2}}, 1\right\}, \text { if } x=\frac{1}{2^{n}}, n=0,1,2, \ldots . \\
\left\{0, \frac{1}{2}\right\}, \text { if } x=0 .
\end{array}\right.
$$


Now

$$
f(x)=d(x, T x)=\left\{\begin{aligned}
\frac{1}{2^{n+1}}, & \text { if } x=\frac{1}{2^{n}}, n=1,2, \ldots \\
0, & \text { if } x=0,1
\end{aligned}\right.
$$

and

$$
f(x)=d(x, S x)=\left\{\begin{aligned}
\frac{3}{2^{n+2}}, & \text { if } x=\frac{1}{2^{n}}, n=1,2, \ldots \\
0, & \text { if } x=0,1
\end{aligned}\right.
$$

Hence $f$ is continuous for both mappings $S$ and $T$. Obviously, $S$ and $T$ are not contractive mappings. It is clear that

$$
H\left(T\left(\frac{1}{2^{n}}\right), T(0)\right)=\frac{1}{2}
$$

Hence

$$
H\left(T\left(\frac{1}{2^{n}}\right), T(0)\right)=\frac{1}{2} \geq \frac{1}{2^{n}}=\left|\frac{1}{2^{n}}-0\right|=d\left(\frac{1}{2^{n}}, 0\right) \quad n=1,2,3 \ldots
$$

For mapping $S: X \rightarrow C(X)$

$$
H\left(S\left(\frac{1}{2^{n}}\right), S(0)\right)=\frac{1}{2}
$$

Hence

$$
H\left(S\left(\frac{1}{2^{n}}\right), S(0)\right)=\frac{1}{2} \geq \frac{1}{2^{n}}=\left|\frac{1}{2^{n}}-0\right|=d\left(\frac{1}{2^{n}}, 0\right), \quad n=1,2,3 \ldots
$$

Furthermore, there exists $y \in I_{0.7}^{x}$, for any $x \in X$, such that $d(y, T(y))=$ $\frac{1}{2} d(x, y)$ and $d(y, S(y))<\frac{1}{2} d(x, y)$, then

$$
H(F(S), F(T))=0
$$

and

$$
\operatorname{Sup}_{x \in X} H(S x, T x)=\frac{1}{4} .
$$

Hence, we get $H(F(S), F(T)) \leq(b-c)^{-1} S u p_{x \in X} H(S x, T x)$.

Theorem 4.2. Let $X$ be a complete metric space and let $T_{n}: X \rightarrow C(X)$ $(n=0,1,2,3, \ldots)$ be multivalued mappings. If there exists a constant $c \in(0,1)$ such that for any $x \in X$, there is $y \in I_{b}^{(n) x}$ satisfying

$$
d\left(y, T_{n} y\right) \leq c d(x, y), \quad \text { for } n=1,2,3,4 \ldots .
$$

If $\lim _{n \rightarrow \infty} H\left(T_{n} x, T_{0} x\right)=0$ uniformly for $x \in X$, then $\lim _{n \rightarrow \infty} H\left(F\left(T_{n}\right), F\left(T_{0}\right)\right)=$ 0 
Proof. Since

$$
\lim _{n \rightarrow \infty} H\left(T_{n}(x), T_{0}(x)\right)=0
$$

uniformly for $x \in X$, it is possible to select $n_{0} \in \mathbb{N}$, such that

$$
\sup _{x \in X} H\left(T_{n} x, T_{0} x\right) \leq(b-c) \epsilon, \text { for all } n \geq n_{0} \text {. }
$$

By proposition 4.1, we have

$$
H\left(F\left(T_{n}\right), F\left(T_{0}\right)\right)<\epsilon, \text { for all } n \geq n_{0} .
$$

Hence

$$
\lim _{n \rightarrow \infty} H\left(F\left(T_{n}\right), F\left(T_{0}\right)\right)=0 .
$$

ACKNOWLEDGEMENTS: The first author gratefully acknowledges The financial support provided by the University Grants Commission (UGC), Government of India.

\section{References}

[1] B. E. Rhoades, Comments on two fixed point iteration methods, J.Math. Anal. Appl., 56 (1976), 741 - 750.

[2] B. Panyanak, Mann and Ishikawa iterative process for multivalued mappings in Banach Spaces, Computers and Mathematics with Applications, 54 (2007), 872-877.

[3] H. K. Xu, Inequalities in Banach Spaces with applications, Nonlinear Anal., 16 (1991), 1127-1138.

[4] J. Schu, Iterative construction of fixed points of asymptotically nonexpansive mappings, J. Math. Anal. Appl., 158 (1991), 407-413.

[5] K. K. Tan and H. K. Xu, Approximating fixed points of nonexpansive mappings by the Ishikawa iteration process, J. Math. Anal. Appl., 178 (1993), 301-308. 
[6] K. P. R. Sastry and G. V. R. Babu, Convergence of Ishikawa iterates for a multivalued mapping with a fixed point, Czechoslovak Mathematical Journal, 55, (2005), 817-826.

[7] L. Ciric, A. Rafiq, N. Cakic and J. S. Ume, Implicit Mann fixed point iterations for pseudo-contractive mappings, Applied Mathematics Letters, 22 (2009), 581-584.

[8] M. O. Osilike and D. I. Igbokwe, Weak and strong convergence theorems for fixed points of pseudocontractions and solutions of monotone type operator equations, Comput. Math. Appl. , 40 (2000), 559-567.

[9] R. P. Agarwal, D. O'Regan and D. R. Sahu, Fixed point theory for Lipschitzian-type mappings with Applications, vol. 6, Springer New York, (2009), p. 192.

[10] S. Ishikawa, Fixed point by a new iteration method, Proc. Amer. Math. Soc., 4(1) (1974), 147-150.

[11] W. R. Mann, Mean value methods in iterations, Proc. Amer. Math. Soc., 4 (1953), 506-510.

[12] Y. Feng and S. Liu, Fixed point theorems for multivalued contractive mappings and multi-valued Caristi type mappings, J. Math. Anal. Appl., 317 (2006), 103-112.

Julee SRIVASTAVA,

Department of Mathematics,

University of Allahabad,

Allahabad-211006, Uttar Pradesh,.

Email: mathjulee@gmail.com

Neeta SINGH,

Department of Mathematics,

University of Allahabad,

Allahabad-211006, Uttar Pradesh,.

Email: n_s32132@yahoo.com 